\title{
Effects of colostrum, feeding method and oral IGF1 on porcine uterine development
}

\author{
Ashley F George ${ }^{1}$, Kathleen M Rahman¹, Dori J Miller², Anne A Wiley², Meredith E Camp ${ }^{1}$, \\ Frank F Bartol ${ }^{2}$ and Carol A Bagnell ${ }^{1}$ \\ ${ }^{1}$ Department of Animal Sciences, Endocrinology and Animal Biosciences Program, Rutgers University, New \\ Brunswick, New Jersey, USA and ${ }^{2}$ Department of Anatomy, Physiology and Pharmacology, Cellular and Molecular \\ Biosciences Program, Auburn University, Auburn, Alabama, USA \\ Correspondence should be addressed to C A Bagnell; Email: cbagnell@sebs.rutgers.edu
}

\begin{abstract}
Nursing ensures lactocrine delivery of maternally derived, milk-borne bioactive factors to offspring, which affects postnatal development of female reproductive tract tissues. Disruption of lactocrine communication for two days from birth (postnatal day (PND) 0) by feeding milk replacer in lieu of nursing or consumption of colostrum alters porcine uterine gene expression globally by PND 2 and inhibits uterine gland genesis by PND 14. Here, objectives were to determine effects of: (1) nursing or milk replacer feeding from birth; (2) a single dose of colostrum or milk replacer and method of feeding and (3) a single feeding of colostrum or milk replacer, with or without oral supplementation of IGF1, administered at birth on aspects of porcine uterine development at 12-h postnatally. Results indicate nursing for $12 \mathrm{~h}$ from birth supports rapid establishment of a uterine developmental program, illustrated by patterns of endometrial cell proliferation, expression of genes associated with uterine wall development and entry into mitosis and establishment of a uterine MMP9/TIMP1 system. A single feeding of colostrum at birth increased endometrial cell proliferation at $12 \mathrm{~h}$, regardless of method of feeding. Oral supplementation of IGF1 was sufficient to support endometrial cell proliferation at $12 \mathrm{~h}$ in replacer-fed gilts, and supplementation of colostrum with IGF1 further increased endometrial cell proliferation. Results indicate that lactocrine regulation of postnatal uterine development is initiated with the first ingestion of colostrum. Further, results suggest IGF1 may be lactocrine-active and support a 12-h bioassay, which can be used to identify uterotrophic lactocrine activity.

Reproduction (2018) 155 259-271
\end{abstract}

\section{Introduction}

Nursing provides a conduit for lactocrine delivery of maternally derived, milk-borne bioactive factors (MbFs) to offspring where they can affect postnatal development as proposed by the lactocrine hypothesis (Yan et al. 2006, Bartol et al. 2008). Data for the pig showed that imposition of a lactocrine-null condition from birth (postnatal day (PND) 0), by gavage feeding a porcine milk replacer in lieu of nursing and colostrum (first milk) consumption, altered patterns of uterine gene expression (Rahman et al. 2016, George et al. 2017) and endometrial cell proliferation by PND 2 (Miller et al. 2013) and inhibited uterine gland development by PND 14 (Miller et al. 2013). Lactocrine deficiency, documented in nursed gilts that consumed minimal amounts of colostrum on the day of birth, had similar anti-uterotrophic effects when evaluated on PND 14 (Bartol et al. 2017). Moreover, adult gilts that were lactocrine deficient on their day of birth displayed reduced lifetime fecundity (Bartol et al. 2013, Vallet et al. 2015). Thus, disruption of lactocrine signaling from birth affects both the program and trajectory of porcine uterine development.

Evidence that lactocrine deficiency on the day of birth leads to permanent impairment of reproductive performance in adult female pigs, as reflected by reduced uterine capacity to support large, viable litters (Vallet et al. 2015), suggests that lactocrine signaling from birth affects the porcine uterine developmental program rapidly. Consistently, when colostrum consumption was delayed $0.5 \mathrm{~h}$ from birth or limited to $12 \mathrm{~h}$ from birth, markers of female reproductive tract (FRT) development, including uterine matrix metalloproteinase-9 (MMP9) and tissue inhibitor of metalloproteinase-1 (TIMP1), as well as cervical MMP9 expression levels on PND 2 were similar to those observed for nursed gilts that consumed colostrum continuously for $48 \mathrm{~h}$ from birth (Ho et al. 2017). Further, a single feeding of colostrum at birth was sufficient to support normal levels of cervical cell proliferation at $12 \mathrm{~h}$ postnatal (Camp et al. 2014). These observations, taken together with data indicating that nursing for as little as one hour from birth is sufficient to establish passive immunity in newborn piglets (Coalson 
\& Lecce 1973), suggest that lactocrine signals supportive of FRT development are likely to be communicated within $12 \mathrm{~h}$ of birth (Bartol et al. 2017).

To the extent that lactocrine signals communicated to nursing female piglets within $12 \mathrm{~h}$ of birth contribute to mechanisms that define the uterine organizational program and reproductive performance in adults, it is important that the biology of uterine development during this early neonatal period be understood. Further, given that the first $12 \mathrm{~h}$ of neonatal life may represent a critical period for lactocrine programming of uterine function (Bagnell et al. 2017), establishment of a model system for study of lactocrine-sensitive uterine organizational events specific to this period is important. Data specific to the developing porcine cervix during this neonatal period (Camp et al. 2014) provide a framework and rationale for establishment of a similar protocol specific to the uterus. In refining that protocol for this purpose, three studies were conducted linked by a common 12-h bioassay design. The objective of Study 1 was to determine whether lactocrine effects on specific aspects of the neonatal uterine organizational program could be detected at $12 \mathrm{~h}$ postnatally in gilts nursed from birth. The objective of Study 2 was to evaluate whether method of feeding a single dose of colostrum affects markers of uterine development at $12 \mathrm{~h}$ postnatally. Finally, Study 3 was conducted to determine if known, potentially lactocrineactive factors found in porcine colostrum, such as insulin-like growth factor 1 (IGF1) (Simmen et al. 1990, Donovan \& Odle 1994, Donovan et al. 1994), could alter uterine histology or patterns of cell proliferation by $12 \mathrm{~h}$ postnatally.

\section{Materials and methods}

\section{Animals and experimental design}

Gilts (Sus scrofa domesticus) were born and raised from an established herd of crossbred (Duroc, Hampshire, Yorkshire and Landrace genetics) pigs at the Swine Unit of the New Jersey Agricultural Experiment Station, Rutgers University. All procedures involving animals were reviewed and approved by the Rutgers Institutional Animal Care and Use Committee and conducted in accordance with the Guide for the Care and Use of Agricultural Animals in Agriculture Research and Teaching (McGlone et al. 2010). Three studies were conducted to establish a 12-h postnatal bioassay for studying lactocrine effects in the uterus, as outlined in Fig. 1. In all studies, care was taken to insure that treatments were balanced for potential effects of litter ( $n=5$ litters for Study 1 (Fig. 1A); $n=10$ litters for Study 2 (Fig. 1B); and $n=6$ litters for the Study 3 (Fig. 1C)). Treatment groups were normalized by number of offspring and male siblings were not removed. Gilts were included in the experiments when minimum body weight at birth was $1.3 \mathrm{~kg}$ based on studies indicating that lower body weight pigs exhibit retarded postnatal development (Rehfeldt \& Kuhn 2006).
A

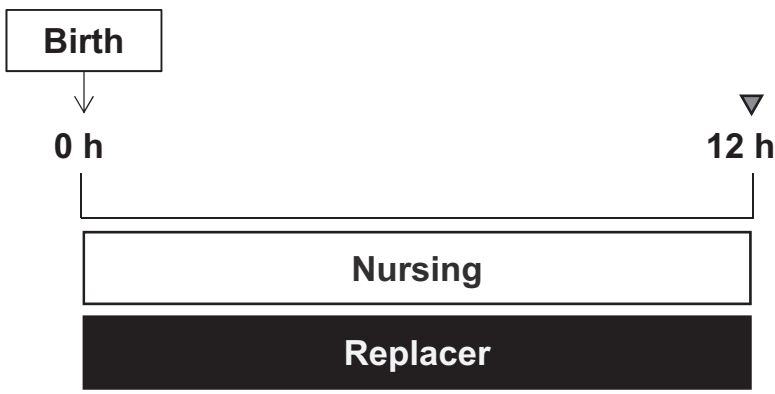

B

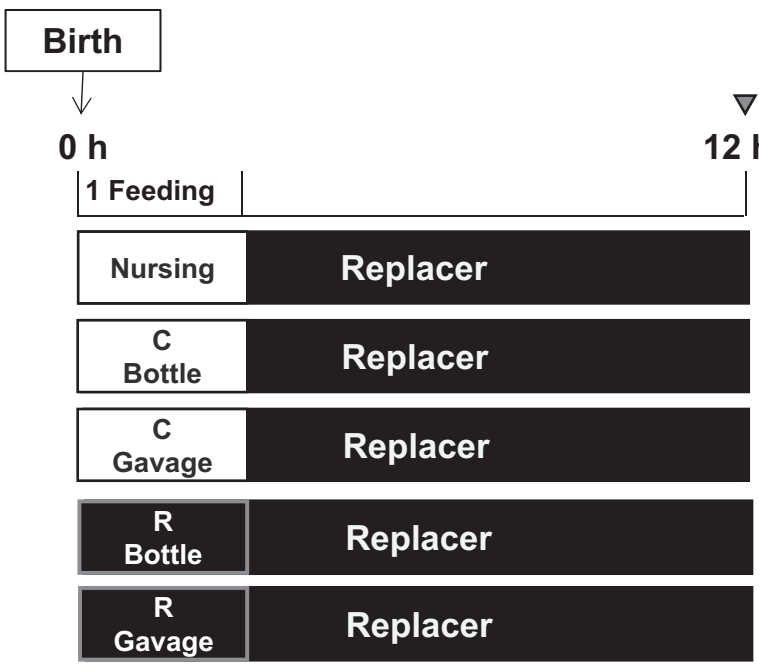

C

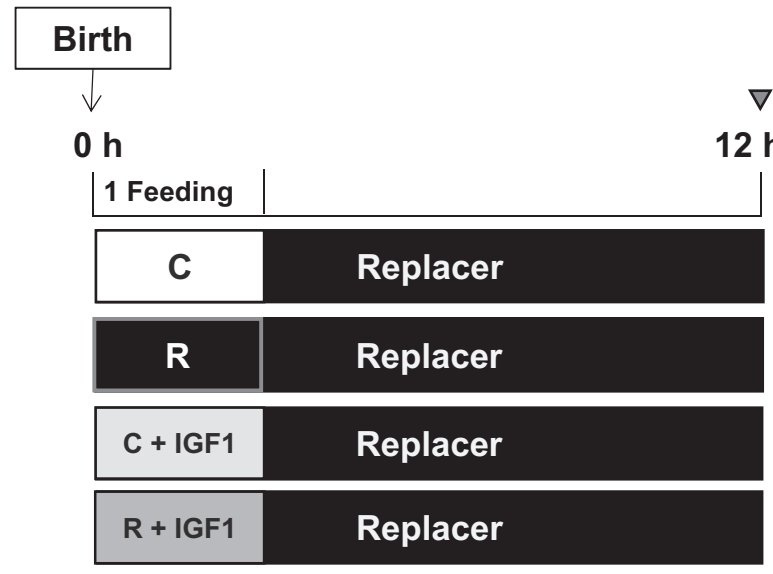

Figure 1 Experimental designs for (A) Study 1; (B) Study 2 and (C) Study 3. (A) Study 1: Gilts were allowed to either nurse ad libitum or were fed milk replacer $(\mathrm{R})$ from birth $(\mathrm{O} \mathrm{h})$ to $12 \mathrm{~h}$ postnatal. (B) Study 2: Gilts were randomly assigned at birth to one of five treatment groups: (1) nursed ad libitum for the first hour after birth or provided a single volume (15 mL/kg BW) of either (2) colostrum, bottle-fed; (3) colostrum, gavage-fed; (4) replacer, bottle-fed or (5) replacer, gavage-fed. Pooled porcine colostrum, collected at $0 \mathrm{~h}$ of lactation, or a commercially complete porcine milk replacer were used for the first feeding in bottle and gavage-fed groups. Thereafter, all gilts were gavage-fed milk replacer until $12 \mathrm{~h}$ of age. (C) Study 3: Gilts were gavage-fed a single dose of colostrum (C) or replacer (R) at birth with or without oral IGF1 followed by replacer feeding by gavage until $12 \mathrm{~h}$ postnatal when uteri were collected indicated by arrowheads; $n=4-6 /$ group. 
Study 1 was conducted to determine the effects of nursing from birth on postnatal uterine development at $12 \mathrm{~h}$ (Fig. 1A). Gilts ( $n=6$ /group) were randomly assigned at birth to nurse ad libitum or to be gavage-fed a commercial porcine milk replacer (30 mL/kg BW/2 h; Advance Liqui-Wean, Milk Specialties Co. Dundee, IL, USA) until $12 \mathrm{~h}$ of age when uteri were collected. Endpoints examined included histology, cell proliferation, gene expression and extracellular matrix (ECM) remodeling proteins.

Study 2 was conducted to determine the effects of a single dose of colostrum or milk replacer and method of feeding on postnatal uterine development at $12 \mathrm{~h}$, as indicated by effects on histology, cell proliferation and gene expression (Fig. 1B). Gilts ( $n=5-6 /$ group) were randomly assigned at birth to one of five treatment groups: (1) nursed ad libitum for the first hour after birth or provided a single volume $(15 \mathrm{~mL} / \mathrm{kg} \mathrm{BW})$ of (2) colostrum by bottle-feeding, (3) colostrum by gavage-feeding, (4) replacer by bottle-feeding or (5) replacer by gavage-feeding. Pooled porcine colostrum, collected at $\mathrm{Oh}$ of lactation, or a commercially complete porcine milk replacer were used for bottle and gavage feeding groups. After the first feeding, gilts were gavage-fed the milk replacer $(30 \mathrm{~mL} / \mathrm{kg}$ BW) every two hours until $12 \mathrm{~h}$ of age when uteri were collected.

Study 3 was conducted to determine the effects of a single dose of colostrum or milk replacer feeding at birth, with or without, oral IGF1 on postnatal endometrial histoarchitecture and cell proliferation at $12 \mathrm{~h}$ (Fig. 1C). Given the small amount of uterine tissue available for analyses in the $12 \mathrm{~h}$ postnatal gilt, the focus of Study 3 was narrowed to measures of uterine histology and cell proliferation. At birth, gilts ( $n=4-6 /$ group) were gavage-fed a single volume $(15 \mathrm{~mL} / \mathrm{kg}$ BW) of either (1) colostrum collected at the onset of parturition ( $0 \mathrm{~h}$ lactation), (2) colostrum supplemented with recombinant human IGF1 (1 $\mu \mathrm{g} / \mathrm{mL}$; Prepro Tech, Rocky Hill, NJ, USA), (3) milk replacer alone or (4) milk replacer supplemented with IGF1 $(1 \mu \mathrm{g} / \mathrm{mL})$. The dose of IGF1 used in these studies was based on the concentration of IGF1 found in porcine colostrum (Simmen et al. 1990). After the initial feeding, all gilts were gavage-fed milk replacer $(30 \mathrm{~mL} / \mathrm{kg}$ BW per $2 \mathrm{~h})$ until $12 \mathrm{~h}$ of age when uteri were collected.

\section{Histomorphometry, immunohistochemistry and image analysis}

Uterine tissues, trimmed of connective tissue, were fixed in Xpress Molecular Fixative (Sakura Finetek, Torrance, CA, USA) and embedded in Paraplast Plus (Thermo Fisher Scientific). For histomorphometry and immunohistochemistry (IHC), uterine cross-sections were cut at $5 \mu \mathrm{m}$ (4-6 sections/gilt) and mounted on SuperFrost Plus slides (Thermo Fisher Scientific). Hematoxylin staining of uterine tissue sections was performed using Harris Modified Hematoxylin (Thermo Fisher Scientific). Entire uterine sections were imaged and measurements were taken using Aperio Imagescope (Leica Biosystems). Endometrial thickness was measured as the distance from the base of the luminal epithelium (LE) to the interface of the endometrium with inner circular myometrium. Stromal cell nuclei within an $800 \mu \mathrm{m}^{2}$ area per animal were counted using ImageJ (National Institute of Health).
For proliferating cell nuclear antigen (PCNA) immunostaining, uterine sections were deparaffinized, rehydrated and subjected to heat-induced epitope retrieval in boiling sodium citrate buffer $(\mathrm{pH}$ 6). For evaluation of cell proliferation, sections were incubated overnight at $4{ }^{\circ} \mathrm{C}$ with mouse anti-rat PCNA antibody (1:100; $0.91 \mu \mathrm{g} / \mathrm{mL}$; clone PC10; Invitrogen). Sections representing all animals from each treatment group were processed together using a VectaStain $\mathrm{ABC}$ elite kit (Vector Laboratories; Burlingame, CA, USA). Following incubation with secondary antibody and $\mathrm{ABC}$ reagent, color was developed using $0.1 \% 3,3^{\prime}$-diaminobenzidine substrate (Sigma-Aldrich). Negative controls were incubated with mouse primary antibody isotype $\operatorname{lgG}(1.06 \mu \mathrm{g} / \mathrm{mL}$; Invitrogen) in place of the primary antibody. Images were obtained using a Qlmaging camera and analyzed using Image Software (National Institute of Health).

\section{PCNA labeling index}

Images were converted to grayscale and analyzed using ImageJ Software (National Institute of Health) following techniques described in Miller et al. (2013). Briefly, nuclei were identified as positive when staining intensity values generated by image analysis were within $25 \%$ of the highest possible intensity value (Miller et al. 2013). Grayscale images were converted to pseudocolor using ImageJ to better illustrate staining intensity. Positively, immunostained cells appear red-yellow on a black background. Labeling index (LI), for PCNA, expressed as a percentage, was determined for the stroma (St) and LE of uteri collected from gilts at $12 \mathrm{~h}$ of age. A minimum of 2000 uterine LE and St cells were counted for each gilt. The PCNA LI for St and LE was expressed as a percentage by dividing the number of PCNA-labeled cells counted in each category by the total number of cells (both labeled and unlabeled) and multiplied by 100 to generate $\mathrm{LI}$ values.

\section{RNA extraction, CDNA synthesis and quantitative PCR (qPCR)}

RNA was isolated from 30 to $40 \mathrm{mg}$ of whole uterine tissue from one uterine horn/animal using the miRNeasy Mini Kit (Qiagen) following the manufacturer's protocol. The RNA concentration was determined using a NanoDrop Spectrophotometer, and RNA integrity was evaluated using an Agilent 2100 Bioanalyzer (Applied Biosystems). Samples with an RNA integrity number $\geq 7.0$ were used for cDNA generation. Reverse transcription was performed using $2 \mu \mathrm{g}$ of total uterine RNA per sample, a Peltier Thermal Cycler-200 (Bio-Rad Laboratories) and the SuperScript III First-Strand Synthesis System (Life Technologies).

Uterine expression of cell cycle and morphoregulatory transcripts including cyclin-dependent kinase 1 (CDK1), CDK2, CDK4, cyclin B1 (CCNB1), wingless-type MMTV integration site family member 5A (WNT5A), WNT7A, homeobox A10 (HOXA10), vascular endothelial growth factor A (VEGFA), relaxin family peptide receptor 1 (RXFP1) and porcine cyclophilin A (PPIA; reference gene) were determined by qPCR.

Briefly, qPCR was performed using Power SYBR Green PCR Master Mix and universal thermal cycling parameters 


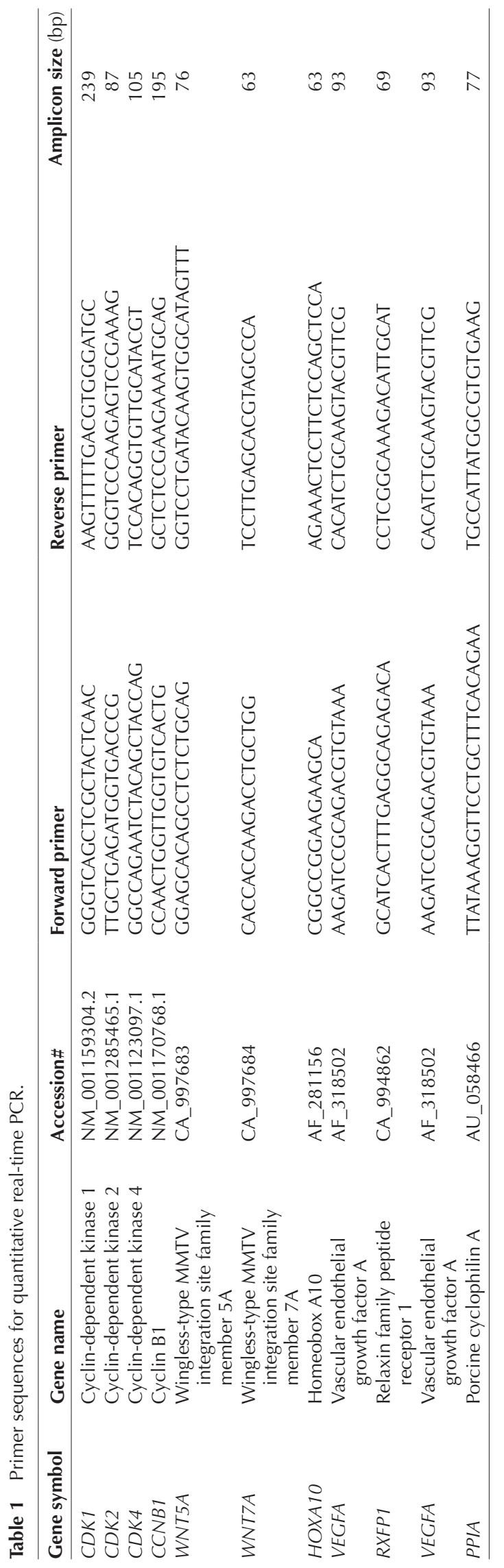

(40 cycles) indicated by the manufacturer on a StepOne Plus System (Applied Biosystems). Primers were designed using Primer Quest software (Integrated DNA Technologies, Inc., Coralville, IA, USA) and synthesized by Sigma-Aldrich. Primer sequences (Table 1) were evaluated for quality by amplifying serial dilutions of the cDNA template. For each transcript, a $50 \mathrm{ng}$ aliquot of cDNA representing each sample was run in triplicate. Control qPCR reactions included substitution of water only, in place of primers and template, to ensure specific amplification in all assays. Dissociation curves for primer sets were evaluated to ensure that no amplicon-dependent amplification occurred. Data were analyzed using the relative standard curve method for quantitation of gene expression as described by the manufacturer (ABI User Bulletin 2, 2001; Applied Biosystems).

\section{Protein extraction and immunoblot analyses}

Total uterine protein was extracted by homogenizing tissues (20 mg) in lysis buffer (1\% Triton X-100, 10\% glycerol, $150 \mathrm{mM}$ Tris- $\mathrm{HCl}, 300 \mathrm{mM} \mathrm{NaCl}$, and $1 \mathrm{mM} \mathrm{MgCl}_{2} ; \mathrm{pH}$ 7.5). For each sample, individual homogenates were centrifuged $(12,000 \mathrm{~g}$ at $4^{\circ} \mathrm{C}$ for $\left.10 \mathrm{~min}\right)$, and protein supernatants were removed and stored at $-80^{\circ} \mathrm{C}$. Protein concentrations were determined using a DC Protein Assay kit (Bio-Rad Laboratories). Uterine proteins $(20 \mu \mathrm{g})$ were resolved on $12 \%$ total monomer, NuPAGE BisTris gels (Invitrogen) under reducing conditions, followed by transfer onto nitrocellulose membranes $(0.45 \mu \mathrm{m}$ pore size; Bio-Rad Laboratories). Relative abundance of uterine MMP9 (pro $92 \mathrm{kDa}$, active $84 \mathrm{kDa}$ ), MMP2 (pro $72 \mathrm{kDa}$, active $66 \mathrm{kDa})$ and TIMP1 $(28 \mathrm{kDa})$ proteins were determined by immunoblotting and densitometry using actin (43 kDa) as the loading control (Ho et al. 2017).

Briefly, membranes were blocked with $10 \%$ nonfat milk powder (NFMP) in TBST buffer (25 mm Tris ( $\mathrm{pH} \mathrm{7.5),}$ $0.14 \mathrm{~mm} \mathrm{NaCl}, 3-\mathrm{mm} \mathrm{KCl}$, and $0.05 \%$ Tween 20) for $1 \mathrm{~h}$ at room temperature. The membranes were incubated with either mouse anti-human MMP2 (1:1000; IM33; EMD Millipore), mouse anti-human MMP9 (1:100; IM09L; EMD Millipore), rabbit anti-human TIMP1 (1:1000; C20; Santa Cruz Biotechnology) or goat anti-human actin antibody (1:3000, C11; Santa Cruz Biotechnology) in TBST-5\% NFMP overnight at $4{ }^{\circ} \mathrm{C}$. Antibodies directed against human MMP2, MMP9 and TIMP1 were validated for use in the neonatal pig uterus and cervix (Ho et al. 2017).

Blots were washed with TBST and incubated with infrared fluorescent dye-conjugated secondary antibodies (1:20,000; LI-COR Biosciences, Lincoln, NE, USA) in TBST-5\% NFMP for $1 \mathrm{~h}$ at room temperature and proteins were visualized with the Odyssey Clx infrared imaging system (LI-COR Biosciences). Positive controls for MMP2, MMP9 and TIMP1 immunoblots consisted of pregnant sow uterine tissue (gestation day 90), as described by Ho et al. (2017). Negative controls consisted of primary antibody substitution with an irrelevant mouse IgG (for MMP2 and MMP9) or rabbit IgG (for TIMP1), in each case as appropriate. Incubation with secondary antibodies alone showed no evidence of crossreactivity with uterine proteins at expected molecular sizes for targeted proteins. 
Protein signals were quantified densitometrically using Image Software (National Institute of Health). All data were corrected for background signals and expressed as target protein to actin ratio. Densitometric analyses of total MMP2 (pro $72 \mathrm{kDa}$, active $66 \mathrm{kDa}$ ) and total MMP9 (pro $92 \mathrm{kDa}$, active $84 \mathrm{kDa}$ ) protein are reported. Immunoblot signals that were below background under identical exposure conditions were recorded as not detectable.

\section{Statistical analysis}

Data were subjected to analysis of variance using General Linear Model procedures (SAS 2013, Cary, NC, USA) and are presented as least squares means $($ LSM) \pm standard error of the mean (S.E.M.). Preplanned comparisons were performed for each study. For Study 1, statistical models considered the main effects of treatment (nursed vs replacer) and, where appropriate, cell compartment (luminal epithelium vs stroma), and their interactions. For Study 2, statistical models considered the main effects of treatment (colostrum vs replacer), method of feeding colostrum (nursing vs bottle and gavage; bottle vs gavage), cell compartment (luminal epithelium vs stroma) and their interactions. For Study 3, statistical models considered the main effects of treatment (colostrum vs replacer), main effects of IGF1 (with vs without IGF1), cell compartment (luminal epithelium vs stroma) and their interactions, as appropriate. Error terms used in tests of significance were based upon expectations of the mean square for error.

\section{Results}

Study 1: Effects of nursing on postnatal endometrial cell proliferation and uterine gene expression at $12 \mathrm{~h}$

Pseudocolor images illustrating the effects of nursing for $12 \mathrm{~h}$ from birth on patterns of PCNA immunostaining, and histograms summarizing PCNA LI data for endometrial luminal epithelium and stroma are presented in Fig. 2. Positively stained cells are bright red-yellow against a blue/black background. Signal indicative of PCNA labeling above background was observed in all endometrial cell compartments. In comparison with gilts nursed for $12 \mathrm{~h}$ from birth, uterine wall development was retarded in replacer-fed gilts, as indicated by reduced PCNA staining (Fig. 2A and B). Mean endometrial PCNA LI was greater $(P<0.001)$ in nursed than in replacer-fed gilts in both stromal and epithelial cell compartments (Fig. 2C). Neither endometrial thickness (185 $\pm 24.5 \mu \mathrm{m})$ nor stromal cell nuclear density ( $30 \pm 1$ cell nuclei/area) were affected by treatment.

Effects of treatment on uterine expression of cell cycle, morphoregulatory and lactocrine-sensitive gene expression are shown in Fig. 2. With regard to cell cycle transcripts, imposition of a lactocrine-null state from birth did not affect uterine CDK2 or CDK4 expression (Fig. 2D and E). However, expression of both CCNB1 (Fig. 2F, P<0.01) and CDK1 (Fig. 2G,
$P<0.001)$ was greater in nursed than replacer-fed gilts at $12 \mathrm{~h}$. For uterine morphoregulatory and lactocrinesensitive gene expression, WNT5A (Fig. $2 \mathrm{H}, P<0.02$ ), HOXA10 (Fig. 2J, $P=0.03$ ), VEGFA (Fig. $2 \mathrm{~K}, P=0.01$ ) and RXFP1 (Fig. $2 \mathrm{~L}, P<0.01$ ) was greater in nursed than in replacer-fed gilts at $12 \mathrm{~h}$. Uterine expression of WNT7A (Fig. 2I) did not differ between nursed and replacer-fed gilts.

\section{Study 1: Effects of nursing on postnatal uterine MMP2, MMP9, and TIMP1 expression at $12 \mathrm{~h}$}

A representative immunoblot (Fig. 3A) illustrating relative abundance of uterine MMP2, MMP9, TIMP1, and actin proteins at $12 \mathrm{~h}$ in nursed and replacer-fed gilts is shown. Treatment did not affect uterine levels of proMMP2 $(72 \mathrm{kDa})$ or MMP2 $(66 \mathrm{kDa})$, which were detected in all tissues (Fig. $3 \mathrm{~A}$ and $\mathrm{B}$ ). Immunoreactive proMMP9 $(92 \mathrm{kDa})$ and MMP9 $(84 \mathrm{kDa})$ levels were greater (Fig. 3B, $P<0.001$ ) at $12 \mathrm{~h}$ in nursed as compared to replacer-fed gilts (Fig. 3A and B). TIMP1 (28 kDa) was detected in uterine tissues at $12 \mathrm{~h}$ in nursed but not in replacer-fed gilts (Fig. 3A and B).

\section{Study 2: Effects of a single dose of colostrum or milk replacer and method of feeding on postnatal endometrial histoarchitecture, cell proliferation, and uterine gene expression at $12 \mathrm{~h}$}

Figure 4 shows the effects of a single dose of colostrum or milk replacer and method of feeding on postnatal endometrial histoarchitecture at $12 \mathrm{~h}$. Neither treatment nor method of feeding affected endometrial thickness (Fig. 4A). However, stromal cell nuclear density was greater (Fig. 4B, $P=0.01$ ) in gilts fed colostrum, by either bottle or gavage, when compared to replacer-fed gilts. Within the colostrum-fed groups, gilts fed colostrum by either bottle or gavage had greater stromal cell nuclear density $(P<0.001)$ compared to those that nursed for the first feeding (Fig. 4B).

Effects of a single dose of colostrum or milk replacer and method of feeding on postnatal endometrial PCNA immunostaining and $\mathrm{LI}$ at $12 \mathrm{~h}$ are illustrated in Fig. 4 . Uterine PCNA immunostaining was more intense in gilts fed a single dose of colostrum (Fig. 4C, D and E) compared to those fed milk-replacer (Fig. 4F and G). Endometrial stromal (Fig. 4H) and epithelial (Fig. 4I) PCNA LI were greater $(P<0.001)$ in gilts fed a single dose of colostrum by either bottle or gavage when compared to replacer-fed gilts. In lactocrine-null gilts, PCNA immunostaining was similar regardless of the method of feeding (Fig. 4F and G). In nursed gilts, uterine PCNA immunostaining was more intense (Fig. 4C) compared to those fed colostrum via bottle or gavage (Fig. 4D and E). However, evaluation of PCNA LI within colostrumfed groups, revealed no effect of method of feeding in the stromal cell compartment (Fig. $4 \mathrm{H}$ ), and a slight 
A

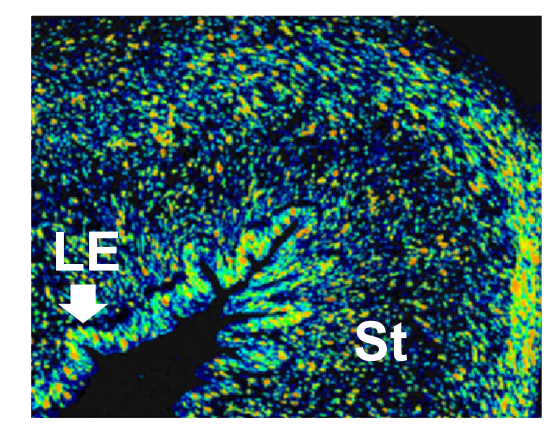

B $\quad$ Replacer (R)

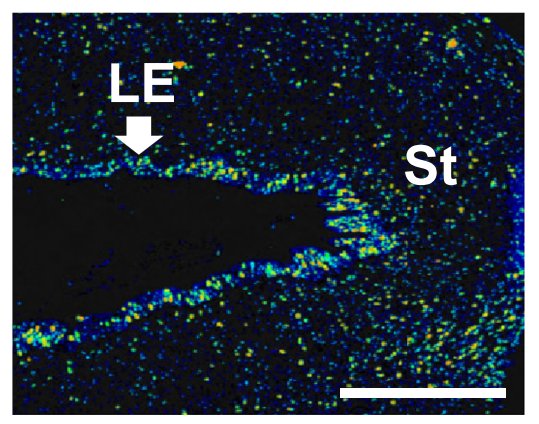

C
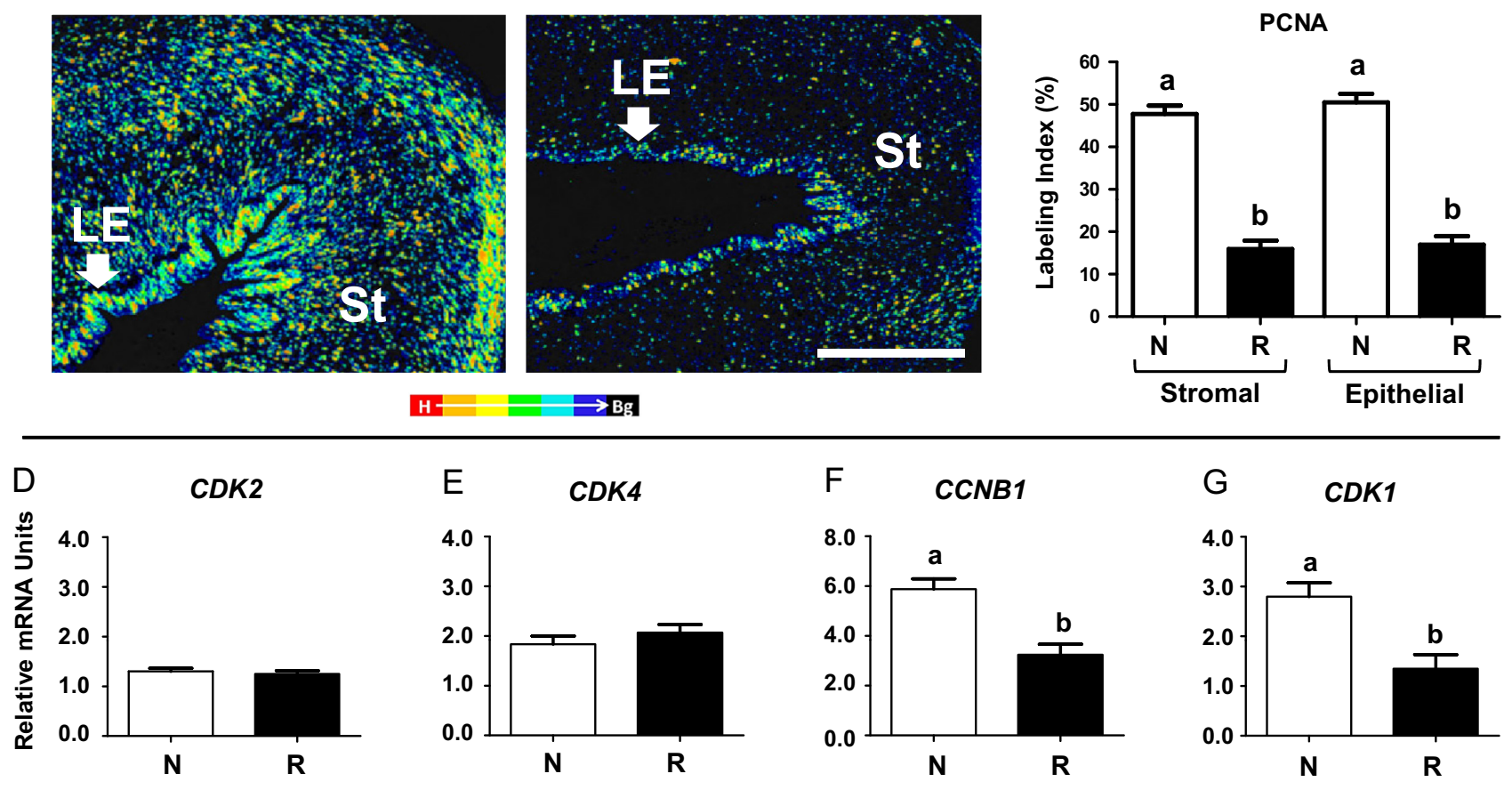

E

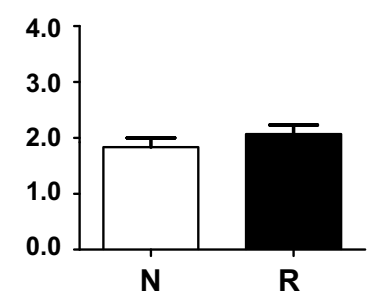

F $\quad$ CCNB1

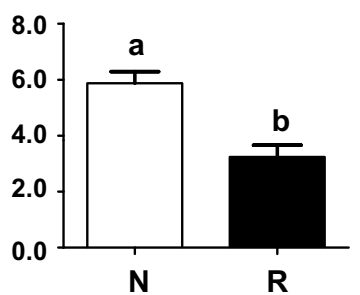

G

CDK1

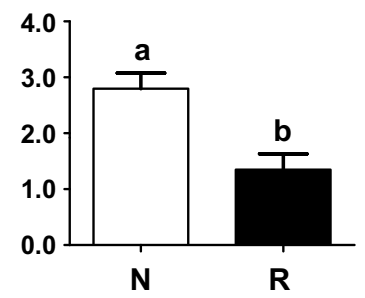

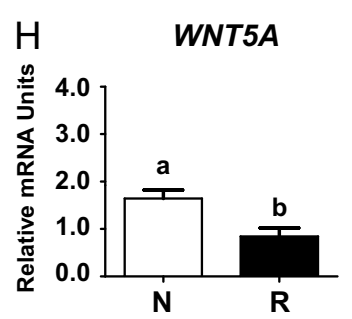
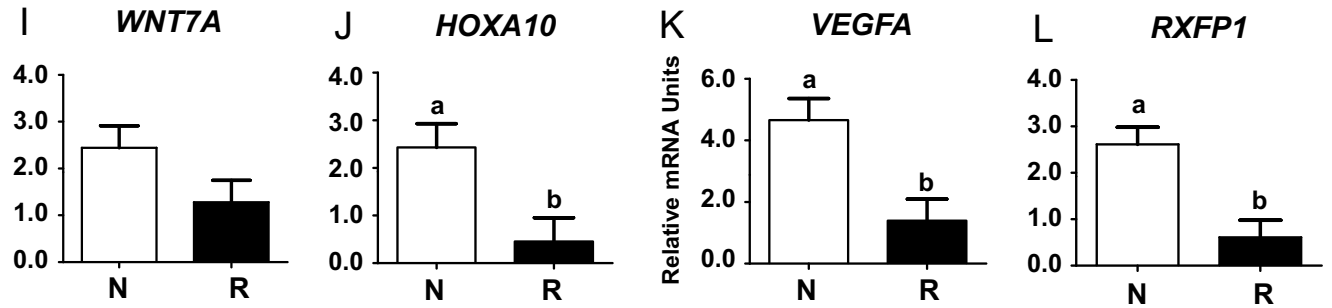

Figure 2 Effects of nursing on postnatal uterine development at $12 \mathrm{~h}$. Pseudocolored images illustrate PCNA labeling patterns in luminal epithelium (LE) and stroma (St) for uterine tissues collected at $12 \mathrm{~h}$ postnatal from (A) nursed and (B) replacer-fed gilts. Signal intensity is indicated by color (bottom legend: $\mathrm{H}$, high, to $\mathrm{Bg}$, background). Positively, immunostained cells appear red-yellow on a black background; scale bar indicates $100 \mu \mathrm{m}$. (C) Endometrial PCNA labeling indices for stromal and epithelial cell compartments are shown. Histograms illustrate the effects of nursing on postnatal uterine expression of cell cycle transcripts (D) CDK2, (E) CDK4, (F) CCNB1, (G) CDK1, as well as morphoregulatory and lactocrine-sensitive transcripts (H) WNT5A, (I) WNT7A, (J) HOXA10, (K) VEGFA and (L) RXFP1 at $12 \mathrm{~h}$. Data were normalized to cyclophilin gene expression. White bars denote nursed and black bars denote replacer-fed groups. Data are presented as LSM \pm S.E.M.; $n=5-6 /$ group. Different letters indicate differences between nursed and replacer-fed gilts at $12 \mathrm{~h}$ postnatal $(P<0.05)$.

increase in nursed as compared with other colostrumfed groups in the epithelium (Fig. 4l; $P=0.07$ ).

Effects of treatment and method of feeding on uterine expression of cell cycle transcripts are depicted in Fig. 5. Uterine expression of CDK2 (Fig. 5A) was similar in gilts fed a single dose of colostrum or replacer. However, within colostrum-fed groups, an effect of method of feeding was identified, with greater $C D K 2$ expression observed in nursed gilts than those fed via bottle or gavage (Fig. 5A, $P=0.03$ ). No effects were identified for CDK4 (Fig. 5B) or CDK1 (Fig. 5D). Uterine CCNB1 expression was moderately lower (Fig. 5C; $P=0.08$ ) in colostrum- as compared with replacer-fed gilts, with no effect of method of feeding identified.

Effects of a single dose of colostrum or milk replacer and method of feeding on postnatal uterine morphoregulatory and lactocrine-sensitive gene expression at $12 \mathrm{~h}$ are depicted in Fig. 5. Relative expression of WNT5A (Fig. 5E), WNT7A (Fig. 5F), HOXA10 (Fig. 5G), VEGFA (Fig. 5H), and RXFP1 (Fig. 5I) were not affected by treatment (colostrum vs milk-replacer). Within colostrum-fed groups, WNT7A expression was greater in nursed gilts as compared with those fed via bottle or gavage (Fig. 5F, $P=0.05)$. A treatment by method of feeding 
A

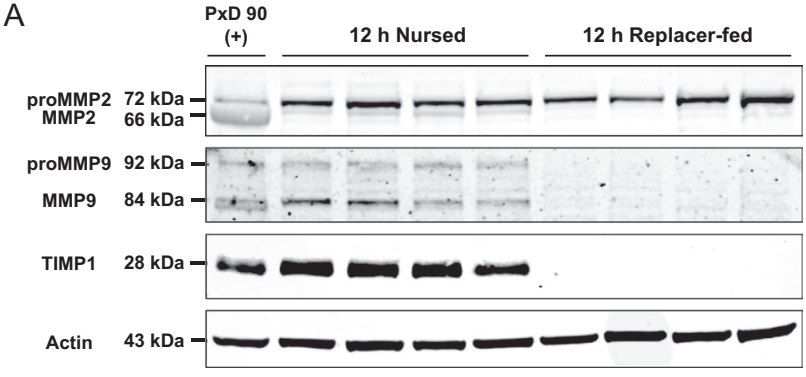

B
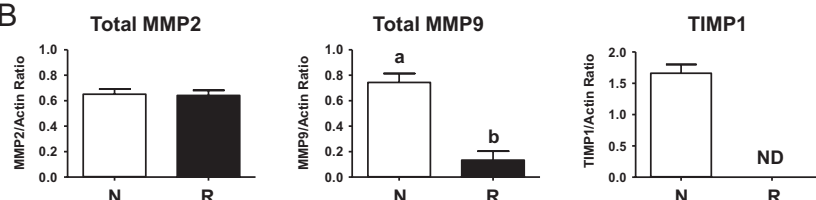

Figure 3 Effects of nursing on postnatal uterine MMP2, MMP9 and TIMP1 protein expression at $12 \mathrm{~h}$. Representative immunoblots (A) are shown. Immunoreactive bands for proMMP2 (72 kDa) and MMP2 (66 kDa), proMMP9 (92 kDa) and MMP9 (86 kDa), as well as for TIMP1 (28 kDa) are indicated. Positive (+) control consisted of uterine tissue from a sow on pregnancy day 90 (PxD 90), as described in 'Materials and methods' section. Densitometric data (B) for the relative expression of total MMP2 $(72+66 \mathrm{kDa})$, total MMP9 $(92+84 \mathrm{kDa})$, and TIMP1 in relation to actin $(43 \mathrm{kDa})$ are presented as $L S M \pm$ S.E.M.; $n=8$ /group. Signal below the detection range is marked as non-detectable (ND). Different letters indicate differences between nursed and replacer-fed gilts at $12 \mathrm{~h}(P<0.05)$.

interaction was identified for HOXA10 expression (Fig. 5G, $P<0.05$ ).

\section{Study 3: Effects of a single dose of colostrum or milk replacer, with or without oral IGF1, on postnatal endometrial histoarchitecture and cell proliferation at $12 \mathrm{~h}$}

Endometrial thickness was not affected by a single feeding of colostrum or milk replacer, with or without oral IGF1 (Fig. 6A). However, stromal cell nuclear density was greater $(P<0.005)$ in colostrum- than with milk replacer-fed gilts (Fig. 6B). Oral supplementation with IGF1 did not affect stromal cell nuclear density in either treatment group (Fig. 6B).

Images illustrating effects of a single feeding of colostrum or milk replacer, with or without oral IGF1, on PCNA immunostaining patterns, and histograms depicting PCNA LI data for uterine tissues at $12 \mathrm{~h}$ are shown in Fig. 6. Uterine wall development was advanced in gilts fed a single oral dose of IGF1, as reflected by the state of development of nascent uterine glands along the uterine lumen. This was not as well defined in gilts fed milk-replacer alone (Fig. 6C, D, E and F). Endometrial PCNA immunostaining was more intense at $12 \mathrm{~h}$ in response to a single feeding of colostrum (Fig. 6C), colostrum with IGF1 (Fig. 6D) or replacer with IGF1 (Fig. 6F) as compared to gilts fed replacer alone (Fig. 6E). Mean PCNA LI data for endometrial stroma (Fig. 6G) and epithelium (Fig. 6H) are shown. Main effects of treatment and IGF1 were identified for both cell compartments $(P<0.05)$. Compared to replacer-fed gilts, a single feeding of colostrum increased PCNA LI $(P<0.05)$. Similarly, a single oral dose of IGF1 increased PCNA $\mathrm{LI}$ in comparison to gilts fed colostrum or milk replacer alone $(P<0.003)$. A treatment by IGF1 interaction was identified for the stromal cell compartment (Fig. 6G, $P<0.002)$. This is illustrated by increased PCNA LI observed in replacer-fed gilts supplemented with IGF1 (Fig. 6G).

\section{Discussion}

Previous studies in the pig showed that nursing is necessary for normal development of porcine uterine (Miller et al. 2013, Rahman et al. 2016, George et al. 2017, Ho et al. 2017), cervical (Camp et al. 2014), and testicular (Rahman et al. 2014) tissues between birth and PND 2. Present results confirm and extend those findings for the uterus by showing that lactocrine effects on aspects of uterine development are detectable as early as $12 \mathrm{~h}$ postnatally. Indeed, a single dose of colostrum at birth was sufficient to affect postnatal uterine development at $12 \mathrm{~h}$, regardless of method of feeding colostrum. Further, results complement findings for the cervix (Camp et al. 2014), indicating that oral IGF1 is bioactive during this period, as reflected by increased uterine cell proliferation. In fact, supplementation of milk-replacer with IGF1 rescued the lactocrine-null phenotype as reflected by PCNA immunostaining patterns. Collectively, results establish the utility of this experimental model system for identification of lactocrine-active factors affecting female reproductive tract development.

At the start of lactation, colostrum is rich in immunoglobulins and MbFs (Coalson \& Lecce 1973, Klobasa et al. 1987, Farmer \& Quesnel 2009). However, over time, its composition changes with the transition to mature milk. In the pig, high concentrations of solids and protein in colostrum decrease linearly within the first $12 \mathrm{~h}$ postnatally (Coalson \& Lecce 1973, Klobasa et al. 1987, Farmer \& Quesnel 2009). Macromolecule uptake by the gastrointestinal tract occurs within the first 24-48 $\mathrm{h}$ after birth, corresponding to the transition from colostrum to mature milk (Leece 1973, Klobasa et al. 1987). Gilts that ingest minimal amounts of colostrum during the first day of postnatal life, display altered patterns of neonatal uterine wall development by PND 14 (Bartol et al. 2017) and reduced adult uterine capacity to support large, viable litters, reflecting permanent impairment of reproductive performance (Vallet et al. 2015). These observations support the idea that lactocrine-sensitive organizational events associated with uterine development within $12-24 \mathrm{~h}$ of birth are critical determinants of uterine programming and functional uterine capacity. 
A

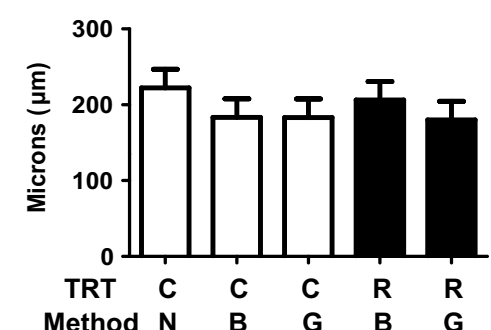

B

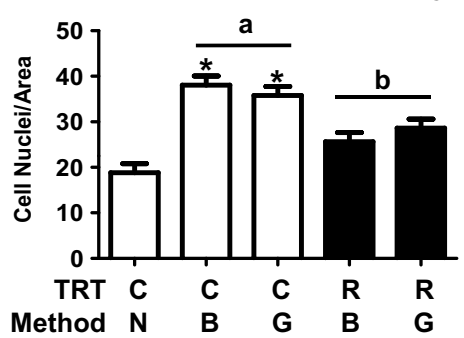

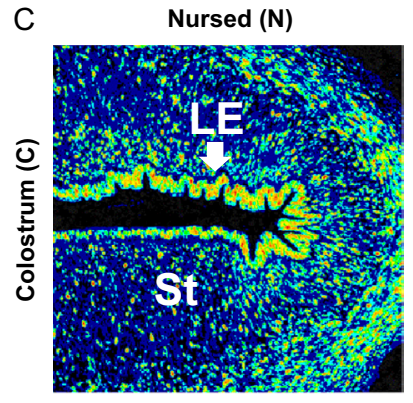

$\mathrm{F}$

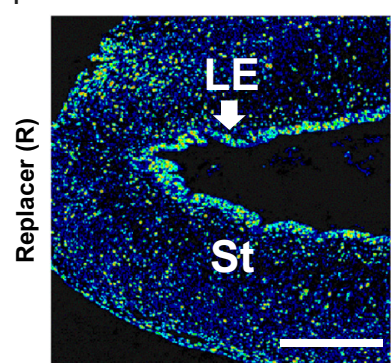

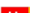

E Gavage-fed (G)

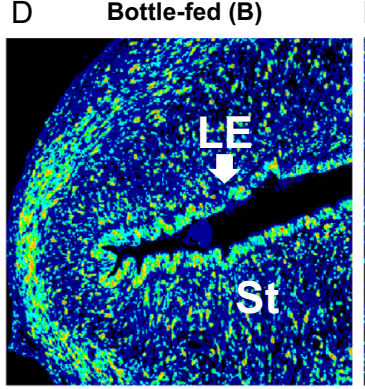

G

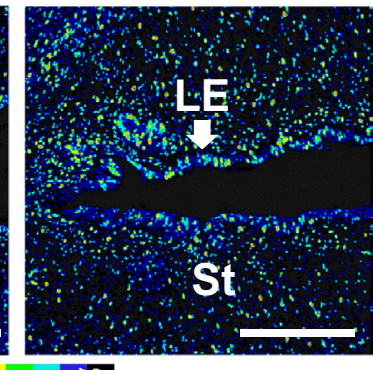

$\mathrm{H}$

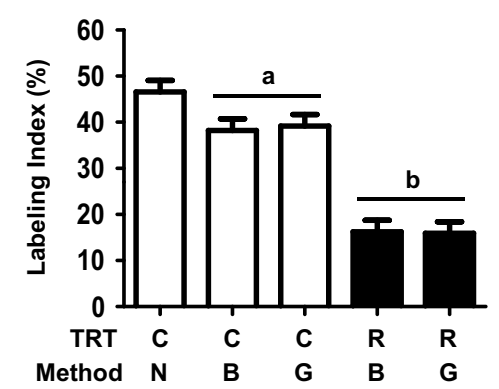

Epithelial PCNA

I

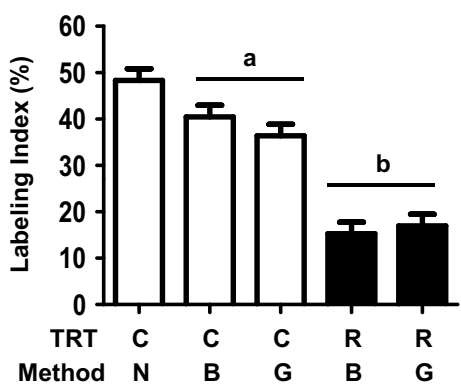

Figure 4 Effects of a single dose of colostrum (C) or milk replacer (R) and method of feeding (nursing $(\mathrm{N})$, bottle-fed $(\mathrm{B})$, and gavage $(\mathrm{G})$ ) on postnatal uterine development at $12 \mathrm{~h}$. Data for (A) endometrial thickness and (B) stromal cell nuclear density at $12 \mathrm{~h}$ are shown. Pseudocolored images illustrate PCNA labeling patterns in luminal epithelium (LE) and stroma (St) for postnatal uterine tissues collected at $12 \mathrm{~h}$ from (C) colostrum, nursed, (D) colostrum, bottle-fed, (E) colostrum, gavage-fed, (F) replacer, bottle-fed, and (G) replacer, gavage-fed gilts. Signal intensity is indicated by color (bottom legend: $\mathrm{H}$, high, to $\mathrm{Bg}$, background). Positively, immunostained cells appear red-yellow on a black background; scale bar indicates $100 \mu \mathrm{m}$. Endometrial PCNA labeling indices for $(\mathrm{H})$ stromal and (I) epithelial cell compartments are shown. Data are expressed as $\mathrm{LSM} \pm$ S.E.M.; $n=5 /$ group. Different letters denote differences between colostrum-fed and replacer-fed gilts $(P \leq 0.01)$. Within colostrum-fed groups, asterisks indicate an effect of method of feeding (nursing vs bottle- or gavage-fed groups; $P<0.001$ ).
Consistent with endometrial histology observed on PND 2 (Miller et al. 2013), endometrial thickness and stromal cell nuclear density were similar in nursed and replacer-fed gilts at $12 \mathrm{~h}$ postnatally. However, imposition of a lactocrine-null state resulted in decreased endometrial stromal and luminal epithelial cell proliferation, as reflected by PCNA LI, similar to effects of treatment observed on PND 2 (Miller et al. 2013). Cell proliferation is regulated by cell cycleassociated gene products (Malumbres \& Barbacid 2009). The cell cycle is defined by four phases: G1, S (DNA synthesis), G2 and M (mitosis) (Malumbres \& Barbacid 2009). Cyclins and CDKs associated with each phase determine cellular progression through the cycle and are implicated in other roles, such as transcription and DNA damage repair (Lim \& Kaldis 2013). Thus, expression patterns of specific cyclins and CDKs are indicative of successful cell division or cell cycle arrest. Mechanistically, CDK4 is activated during G1 phase, in preparation for DNA replication, and CDK2 is involved in the G1/S DNA damage checkpoint, as well as S/G2 transitions (Malumbres \& Barbacid 2009). Only CDK1 is essential for cell cycle progression and mitosis in most cell types (Malumbres \& Barbacid 2009). Therefore, it was not unexpected that uterine expression of $C D K 2$ and CDK4 were not lactocrine sensitive. However, uterine expression of CCNB1 (Cyclin B1) and CDK1 increased in nursed as compared to replacer-fed gilts 

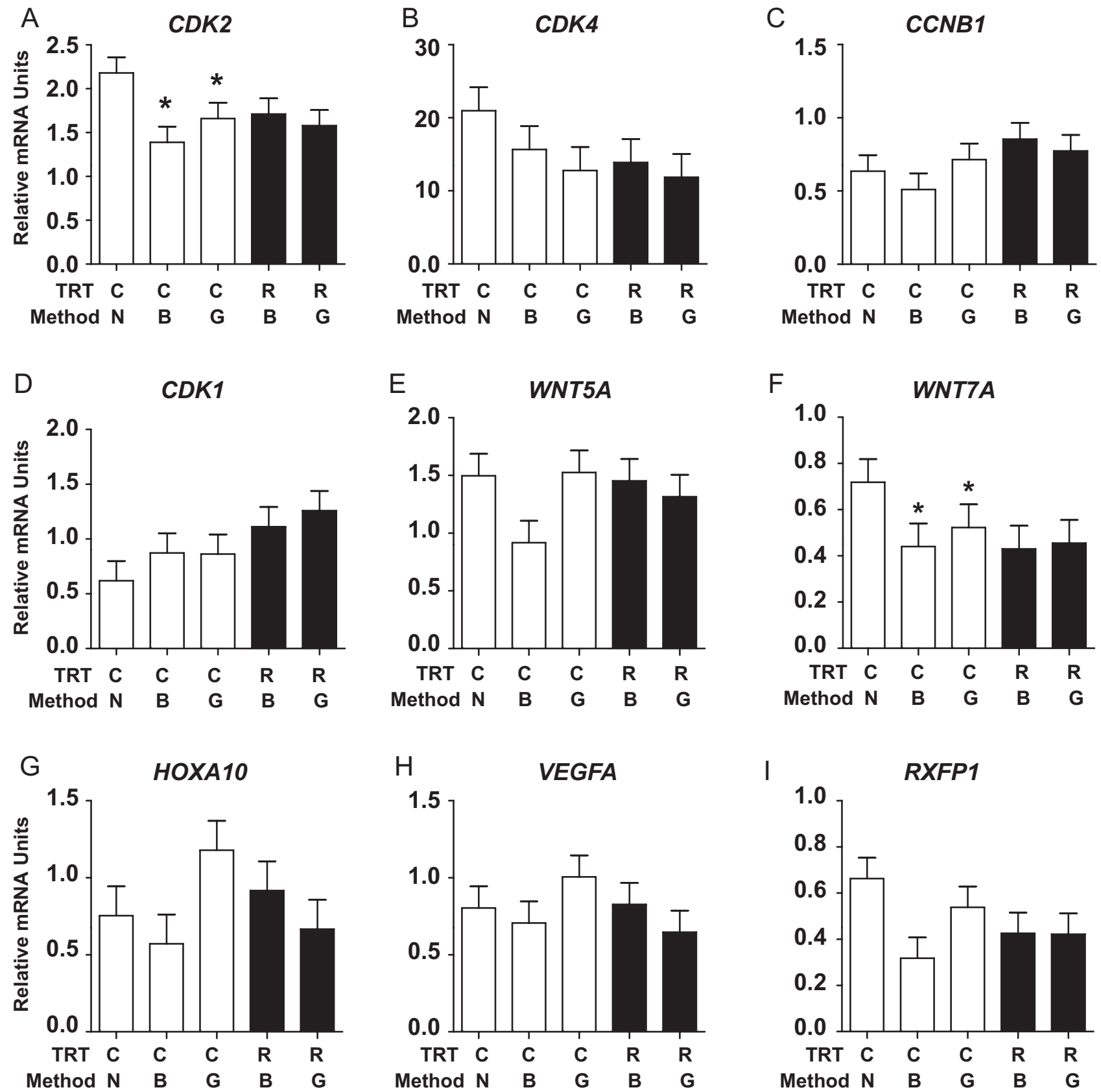

Figure 5 Effects of a single dose of colostrum $(C)$ or milk replacer $(R)$ and method of feeding (nursing $(N)$, bottle-fed (B), and gavage $(G))$ on postnatal uterine gene expression at $12 \mathrm{~h}$. Cell cycle transcript expression for (A) CDK2, (B) CDK4, (C) CCNB1 and (D) CDK1, as well as morphoregulatory and lactocrine-sensitive transcript expression for (E) WNT5A, (F) WNT7A, (G) HOXA10, (H) VEGFA and (I) RXFP1 at $12 \mathrm{~h}$ are shown. Data were normalized to cyclophilin gene expression and are presented as LSM S.E.M.; $n=5$ /group. Within colostrum-fed groups, asterisks indicate an effect of method of feeding (nursing vs bottle- or gavage-fed groups: $C D K 2, P=0.03 ; W N T 7 A, P<0.05$ ). A treatment by method of feeding interaction was identified for HOXA10 $(P<0.05)$.

postnatally at $12 \mathrm{~h}$. Considering that Cyclin B1-CDK1 complexes are necessary for cellular entry into mitosis, this lactocrine effect suggests that mitogenic factors in colostrum support uterine cell division and ultimately, proliferation, as indicated by the increase in PCNA LI reported here.
Communication between stroma and epithelium is required for uterine morphogenesis (Cooke et al. 2013). Previous in situ hybridization studies showed that a Hoxa/Wnt expression axis develops in the porcine uterus between birth and PND 14 (Bartol et al. 2006). Later studies showed that nursing supports specific expression 

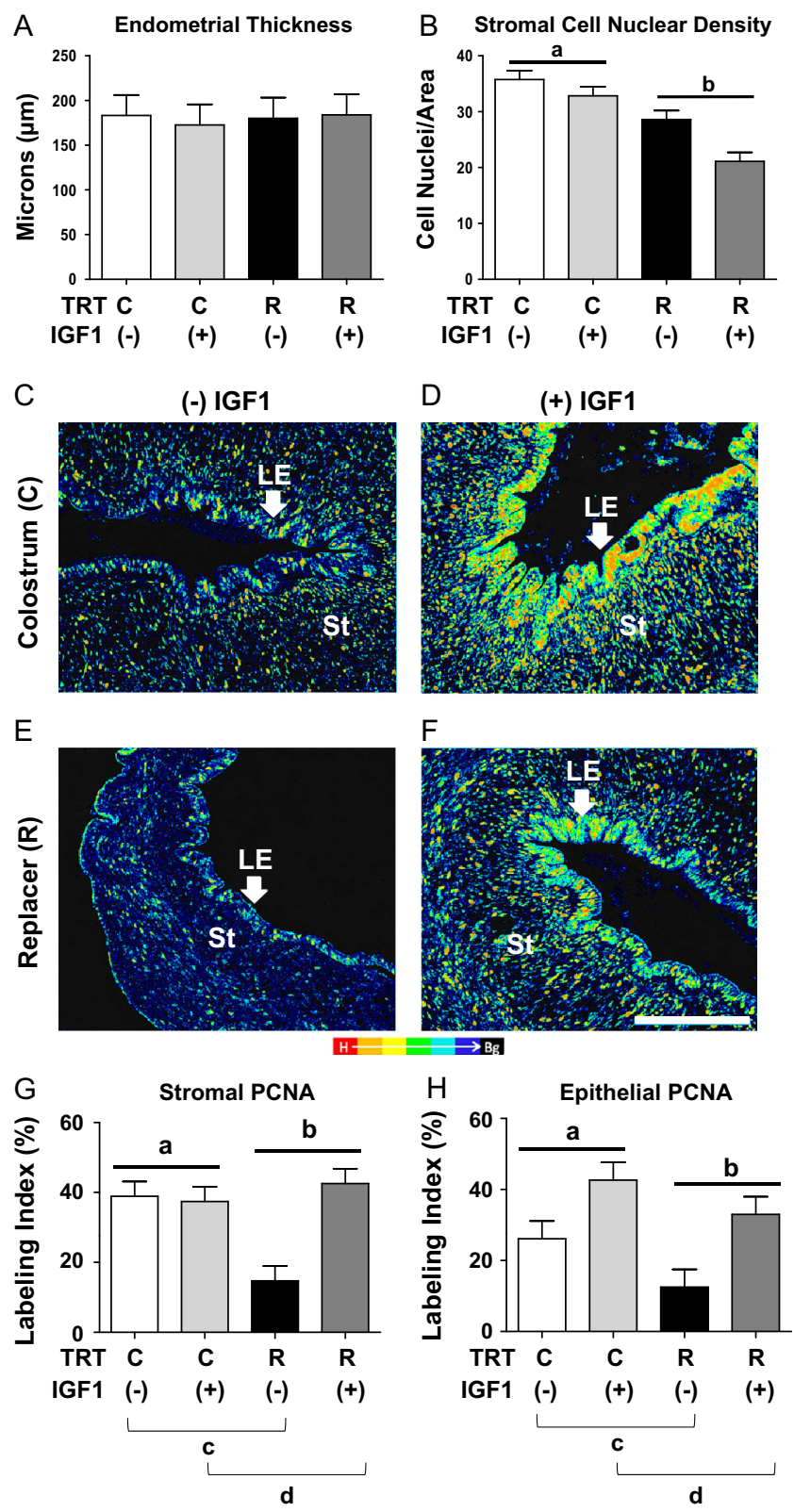

Figure 6 Effects of a single dose of colostrum $(C)$ or milk replacer $(R)$, with (+) or without (-) oral IGF1, on postnatal endometrial histology and PCNA immunostaining patterns at $12 \mathrm{~h}$. Data for endometrial thickness (A) and stromal cell nuclear density (B) are shown. Pseudocolored images illustrate PCNA labeling patterns in luminal epithelium (LE) and stroma (St) for uterine tissues collected at $12 \mathrm{~h}$ from gilts fed a single dose of (C) colostrum, without IGF1, (D) colostrum, with IGF1, (E) milk replacer, without IGF1, or (F) milk replacer, with IGF1. Signal intensity is indicated by color (bottom legend). Positively, immunostained cells appear red-yellow on a black background; scale bar indicates $100 \mu \mathrm{m}$. Endometrial PCNA labeling indices for $(\mathrm{G})$ stromal and $(\mathrm{H})$ epithelial cell compartments are shown. Data are presented as LSM \pm s.E.M.; $n=6$ /group. Letters a and $\mathrm{b}$ indicate differences between colostrum-fed and replacer-fed groups $(P<0.05)$. Letters $\mathrm{c}$ and $\mathrm{d}$ indicate differences between gilts fed colostrum or replacer with and without IGF1 $(P<0.05)$. See text for detailed descriptions of these relationships. patterns of other markers of uterine development, including ESR1, VEGFA and RXFP1 (Chen et al. 2011, Miller et al. 2013). As the uterus develops, these morphoregulatory transcripts are temporospatially expressed (Bartol et al. 2006, Chen et al. 2011, Miller et al. 2013). In the present study, nursing increased postnatal uterine expression of WNT5A and HOXA10 transcripts at $12 \mathrm{~h}$, consistent with stromal expression that increased between birth and PND 14 (Bartol et al. 2006). At $12 \mathrm{~h}$, uterine WNT7A expression was unaffected by nursing. Studies in mice showed that WNT7A is required for the development of the uterine Hoxa/Wnt expression axis which, in turn, is necessary for proper radial patterning of the female reproductive tract (Miller \& Sassoon 1998). Uterine VEGFA expression was unaffected by nursing for two days from birth (Chen et al. 2011, Miller et al. 2013). However, uterine expression of VEGFA increased in nursed as compared to replacer-fed animals at $12 \mathrm{~h}$, suggesting lactocrine-mediated transcription occurs prior to PND 2. Postnatal uterine expression of RXFP1 increased in nursed vs replacer-fed gilts at $12 \mathrm{~h}$. However, nursing from birth and relaxin administration decreased uterine expression of RXFP1 on PND 2 (Chen et al. 2011, Miller et al. 2013). This apparent inconsistency may indicate that lactocrine transmission of milk-borne relaxin (Frankshun et al. 2011) may be insufficient to downregulate uterine RXFP1 expression by $12 \mathrm{~h}$ postnatally. While serum relaxin in nursed pigs is elevated within 24-48 h of birth (Yan et al. 2006), the extent to which relaxin and other MbFs are transmitted to nursing pigs prior to $24 \mathrm{~h}$ is unknown.

In addition to stromal-epithelial cell communication, cell-extracellular matrix interactions are required to support the development of uterine glands ( $\mathrm{Hu}$ et al. 2004). The MMP/TIMP system regulates synthesis and degradation of the ECM, necessary for tubulogenesis and branching morphogenesis in several tissues (Werb \& Chin 1998). Analysis of the porcine uterine transcriptome between birth and PND 2 identified age- and lactocrinesensitive transcripts within the plasminogen-activating network, including MMPs and TIMPs (Rahman et al. 2016). Further, a recent study determined that nursing for $12 \mathrm{~h}$ from birth was sufficient for the expression of uterine MMP9 and TIMP1, as well as cervical MMP9, at levels equivalent to those observed in gilts nursed for $48 \mathrm{~h}$ from birth (Ho et al. 2017). Consistently, nursing from birth until $12 \mathrm{~h}$ is required for normal uterine expression of MMP9 and TIMP1. Similar to previous reports (Chen et al. 2011, Ho et al. 2017), uterine MMP2 expression was not lactocrine sensitive. Results reinforce observations that nursing for $12 \mathrm{~h}$ from birth is sufficient to provide lactocrine support of the developing neonatal porcine uterus, effects of which are detectable by $12 \mathrm{~h}$.

Studies on the postnatal cervix showed that a single feeding of colostrum, but not milk replacer, was sufficient to support cervical cell proliferation at $12 \mathrm{~h}$ 
(Camp et al. 2014). Data presented here extend these findings by showing that a single feeding of colostrum at birth increased stromal cell nuclear density, as well as endometrial stromal and epithelial cell proliferation at $12 \mathrm{~h}$. These responses were not reflected by associated changes in endometrial thickness or uterine expression of cell cycle or morphoregulatory transcripts. By contrast, as described earlier, nursing for $12 \mathrm{~h}$ from birth increased uterine expression of some cell cyclerelated and morphoregulatory genes at $12 \mathrm{~h}$ postnatal. It is important to note that mRNA measurements do not always correlate with protein expression. One possible explanation for this is that transcription is a relatively early, rapid event and mRNAs are typically less stable than proteins (Vogel \& Marcotte 2012). In this regard, it is not surprising that for an acute treatment, defined by a single feeding of colostrum at birth, only differences in PCNA immunostaining patterns were identified at $12 \mathrm{~h}$. Thus, as reported previously (Ho et al. 2017), duration of nursing from birth is important to support normal uterine expression patterns of lactocrine-sensitive gene products. It will be important to determine the extent to which lactocrine signaling is required to support uterine development within this $12-\mathrm{h}$ window.

In addition to nursing, other methods of feeding (colostrum delivery) and related maternal-neonatal interactions have the potential to affect the development (Curley \& Champagne 2016). Here, methods of feeding were evaluated for colostrum-fed groups. For the majority of postnatal endpoints examined at $12 \mathrm{~h}$, no effects of feeding method were identified. For colostrum-fed gilts, main effects of feeding method (nursed vs bottleand gavage-fed) were identified only for endometrial stromal cell nuclear density and uterine CDK2 and WNT7A expression. This may reflect differences in the quantity or quality of colostrum consumed in a single nursing bout compared to that delivered in a bottle or gavage feeding $(15 \mathrm{~mL} / \mathrm{kg}$ BW/h) (Houle et al. 2000). Colostrum consumption during nursing varies substantially (Devillers et al. 2011) and can be influenced by multiple factors including birth weight, birth rank, litter size (Devillers et al. 2007, 2011) and teat position (Wu et al. 2010). Still, the preponderance of data suggests that method of feeding colostrum does not affect postnatal porcine uterine development overtly at $12 \mathrm{~h}$. Nevertheless, it will be important to consider the potential effects of feeding method in future studies of this kind. Evidence of lactocrine effects on both patterns of neonatal uterine wall development and lifetime fecundity in nursed gilts that consumed minimal amounts of colostrum from birth, as defined by birth day immunoglobulin immunocrit (Vallet et al. 2015, Bartol et al. 2017), provide support for the lactocrine hypothesis unbiased by feeding method.

An earlier study showed that IGF1, present in high concentrations in porcine colostrum (Simmen et al.
1988), increased cervical cell proliferation by $12-\mathrm{h}$ postnatal when supplemented orally in milk replacer at birth (Camp et al. 2014). Here, in contrast to data for the cervix (Camp et al. 2014), results showed positive effects of IGF1 on endometrial cell proliferation when supplemented in either milk replacer or colostrum. Moreover, effects of IGF1 were additive when administered in colostrum. Collectively, data support the idea that peptide growth factors such as IGF1 can be lactocrine-active when administered at birth. Results also suggest that strategic supplementation of milk replacer with lactocrine-active peptides could enable rescue of an aberrant, lactocrine-deficient developmental program (Bagnell et al. 2017, Bartol et al. 2017).

Studies in multiple species, including rhesus macaques (Hinde et al. 2015), rodents (Nusser \& Frawley 1997, Liu et al. 2014) and marsupials (Nicholas et al. 1997, Trott et al. 2003), as well as the pig (Vallet et al. 2015), indicate the importance of nursing, as well as the quality and quantity of colostrum consumed, on lactocrine programming of developing tissues. Prior to this report, examination of lactocrine effects on neonatal porcine uterine development focused on the period between birth and PND 2 (Chen et al. 2011, Miller et al. 2013, Rahman et al. 2016, George et al. 2017, Ho et al. 2017). However, evidence that minimal colostrum consumption on the day of birth affects patterns of uterine wall development with lasting consequences in adulthood (Vallet et al. 2015, Bartol et al. 2017) indicates lactocrine effects on the uterine organizational program occur within $24 \mathrm{~h}$ postnatally. Data presented here support this concept. Evidence that, regardless of method, a single feeding of colostrum at birth supports normal patterns of endometrial cell proliferation at $12-\mathrm{h}$ suggests that lactocrine regulation of postnatal uterine development is initiated with the first ingestion of colostrum.

\section{Declaration of interest}

The authors declare that there is no conflict of interest that could be perceived as prejudicing the impartiality of the research reported.

\section{Funding}

This work was supported by USDA-NRI-2013-67016-20523 (to F F B and C A B) and NSF-EPS-1158862 (to F F B).

\section{Acknowledgements}

The authors thank L Comerford, F McCloskey, and R Potosky in the Rutgers Animal Care Program and the Rutgers University undergraduate student research assistants of 'Sow Watch Club' for their contributions to these studies. Frank $F$ Bartol and Carol A Bagnell: Joint senior authors. 


\section{References}

Bagnell CA, Ho TY, George AF, Wiley AA, Miller DJ \& Bartol FF 2017 Maternal lactocrine programming of porcine reproductive tract development. Molecular Reproduction and Development 84 957-968. (https://doi.org/10.1002/mrd.22815)

Bartol FF, Wiley AA \& Bagnell CA 2006 Uterine development and endometrial programming. Society of Reproduction and Fertility Supplement 62 113-130.

Bartol FF, Wiley AA \& Bagnell CA 2008 Epigenetic programming of porcine endometrial function and the lactocrine hypothesis. Reproduction in Domestic Animals 43 (Supplement 2) 273-279. (https://doi.org/10.1111/ j.1439-0531.2008.01174.x)

Bartol FF, Wiley AA, Miller DJ, Silva AJ, Roberts KE, Davolt ML, Chen JC, Frankshun AL, Camp ME, Rahman KM et al. 2013 Lactation Biology Symposium: lactocrine signaling and developmental programming. Journal of Animal Science 91 696-705. (https://doi.org/10.2527/ jas.2012-5764)

Bartol FF, Wiley AA, George AF, Miller DJ \& Bagnell CA 2017 Physiology and endocrinology symposium: postnatal reproductive development and the lactocrine hypothesis. Journal of Animal Science 95 2200-2210. (https://doi.org/10.2527/jas.2016.1144)

Camp ME, Wiley AA, Boulos MB, Rahman KM, Bartol FF \& Bagnell CA 2014 Effects of age, nursing, and oral IGF1 supplementation on neonatal porcine cervical development. Reproduction 148 441-451. (https://doi. org/10.1530/REP-14-0257)

Chen JC, Frankshun AL, Wiley AA, Miller DJ, Welch KA, Ho TY, Bartol FF \& Bagnell CA 2011 Milk-borne lactocrine-acting factors affect gene expression patterns in the developing neonatal porcine uterus. Reproduction 141 675-683. (https://doi.org/10.1530/REP-10-0320)

Coalson JA \& Lecce JG 1973 Influence of nursing intervals on changes in serum proteins (immunoglobulins) in neonatal pigs. Journal of Animal Science 36 381-385. (https://doi.org/10.2527/jas1973.362381x)

Cooke PS, Spencer TE, Bartol FF \& Hayashi K 2013 Uterine glands: development, function and experimental model systems. Molecular Human Reproduction 19 547-558. (https://doi.org/10.1093/molehr/gat031)

Curley JP \& Champagne FA 2016 Influence of maternal care on the developing brain: mechanisms, temporal dynamics and sensitive periods. Frontiers in Neuroendocrinology 40 52-66. (https://doi.org/10.1016/j. yfrne.2015.11.001)

Devillers N, Farmer C, Le Dividich J \& Prunier A 2007 Variability of colostrum yield and colostrum intake in pigs. Animal 1 1033-1041. (https://doi.org/10.1017/S175173110700016X)

Devillers N, Le Dividich J \& Prunier A 2011 Influence of colostrum intake on piglet survival and immunity. Animal 5 1605-1612. (https://doi. org/10.1017/S175173111100067X)

Donovan SM \& Odle J 1994 Growth factors in milk as mediators of infant development. Annual Review of Nutrition 14 147-167. (https://doi. org/10.1146/annurev.nu.14.070194.001051)

Donovan SM, McNeil LK, Jimenez-Flores R \& Odle J 1994 Insulin-like growth factors and insulin-like growth factor binding proteins in porcine serum and milk throughout lactation. Pediatric Research 36 159-168. (https://doi.org/10.1203/00006450-199408000-00005)

Farmer C \& Quesnel H 2009 Nutritional, hormonal, and environmental effects on colostrum in sows. Journal of Animal Science 87 56-64. (https://doi.org/10.2527/jas.2008-1203)

Frankshun AL, Ho TY, Reimer DC, Chen J, Lasano S, Steinetz BG, Bartol FF \& Bagnell CA 2011 Characterization and biological activity of relaxin in porcine milk. Reproduction 141 373-380. (https://doi.org/10.1530/ REP-10-0401)

George AF, Rahman KM, Camp ME, Prasad N, Bartol FF \& Bagnell CA 2017 Defining age- and lactocrine-sensitive elements of the neonatal porcine uterine microRNA-mRNA interactome. Biology of Reproduction 96 327-340. (https://doi.org/10.1093/biolre/iox001)

Hinde K, Skibiel AL, Foster AB, Del Rosso L, Mendoza SP \& Capitanio JP 2015 Cortisol in mother's milk across lactation reflects maternal life history and predicts infant temperament. Behavioral Ecology 26 269-281. (https://doi.org/10.1093/beheco/aru186)

Ho TY, Rahman KM, Camp ME, Wiley AA, Bartol FF \& Bagnell CA 2017 Timing and duration of nursing from birth affect neonatal porcine uterine matrix metalloproteinase 9 and tissue inhibitor of metalloproteinase 1 .
Domestic Animal Endocrinology 59 1-10. (https://doi.org/10.1016/j. domaniend.2016.10.002)

Houle VM, Park YK, Laswell SC, Freund GG, Dudley MA \& Donovan SM 2000 Investigation of three doses of oral insulin-like growth factor-I on jejunal lactase phlorizin hydrolase activity and gene expression and enterocyte proliferation and migration in piglets. Pediatric Research 48 497-503. (https://doi.org/10.1203/00006450-200010000-00013)

Hu J, Zhang X, Nothnick WB \& Spencer TE 2004 Matrix metalloproteinases and their tissue inhibitors in the developing neonatal mouse uterus. Biology of Reproduction 71 1598-1604. (https://doi.org/10.1095/ biolreprod.104.031559)

Klobasa F, Werhahn E \& Butler JE 1987 Composition of sow milk during lactation. Journal of Animal Science 64 1458-1466. (https://doi. org/10.2527/jas1987.6451458x)

Leece JG 1973 Effect of dietary regimen on cessation of uptake of macromolecules by piglet intestinal epithelium (closure) and transport to the blood. Journal of Nutrition 103 751-756.

Lim S \& Kaldis P 2013 Cdks, cyclins and CKIs: roles beyond cell cycle regulation. Development 140 3079-3093. (https://doi.org/10.1242/ dev.091744)

Liu B, Zupan B, Laird E, Klein S, Gleason G, Bozinoski M, Gal Toth J \& Toth M 2014 Maternal hematopoietic TNF, via milk chemokines, programs hippocampal development and memory. Nature Neuroscience 17 97-105. (https://doi.org/10.1038/nn.3596)

Malumbres M \& Barbacid M 2009 Cell cycle, CDKs and cancer: a changing paradigm. Nature Reviews Cancer 9 153-166. (https://doi.org/10.1038/ nrc2602)

Miller C \& Sassoon DA 1998 Wnt-7a maintains appropriate uterine patterning during the development of the mouse female reproductive tract. Development 125 3201-3211.

Miller DJ, Wiley AA, Chen JC, Bagnell CA \& Bartol FF 2013 Nursing for 48 hours from birth supports porcine uterine gland development and endometrial cell compartment-specific gene expression. Biology of Reproduction 88 4. (https://doi.org/10.1095/biolrepord.112.105056)

Nicholas K, Simpson K, Wilson M, Trott J \& Shaw D 1997 The tammar wallaby: a model to study putative autocrine-induced changes in milk composition. Journal of Mammary Gland Biology and Neoplasia 2 299-310. (https://doi.org/10.1023/A:1026392623090)

Nusser KD \& Frawley S 1997 Depriving neonatal rats of milk from early lactation has long-term consequences on mammotrope development. Endocrine 7 319-323. (https://doi.org/10.1007/BF02801325)

Rahman KM, Lovich JE, Lam C, Camp ME, Wiley AA, Bartol FF \& Bagnell CA 2014 Nursing supports neonatal porcine testicular development. Domestic Animal Endocrinology 48 84-92. (https://doi.org/10.1016/j. domaniend.2014.02.006)

Rahman KM, Camp ME, Prasad N, McNeel AK, Levy SE, Bartol FF \& Bagnell CA 2016 Age and nursing affect the neonatal porcine uterine transcriptome. Biology of Reproduction 94 46. (https://doi.org/10.1095/ biolreprod.115.136150)

Rehfeldt C \& Kuhn G 2006 Consequences of birth weight for postnatal growth performance and carcass quality in pigs as related to myogenesis. Journal of Animal Science 84 (Supplement) E113-E123. (https://doi. org/10.2527/2006.8413_supplE113x)

Simmen FA, Simmen RC \& Reinhart G 1988 Maternal and neonatal somatomedin C/insulin-like growth factor-I (IGF-I) and IGF binding proteins during early lactation in the pig. Developmental Biology 130 16-27. (https://doi.org/10.1016/0012-1606(88)90409-5)

Simmen FA, Whang KY, Simmen RC, Peterson GA, Bishop MD \& Irvin KM 1990 Lactational variation and relationship to postnatal growth of insulin-like growth factor-I in mammary secretions from genetically diverse sows. Domestic Animal Endocrinology 7 199-206. (https://doi. org/10.1016/0739-7240(90)90026-V)

Trott JF, Simpson KJ, Moyle RL, Hearn CM, Shaw G, Nicholas KR \& Renfree MB 2003 Maternal regulation of milk composition, milk production, and pouch young development during lactation in the tammar wallaby (Macropus eugenii). Biology of Reproduction 68 929-936. (https://doi.org/10.1095/biolreprod.102.005934)

Vallet JL, Miles JR, Rempel LA, Nonneman DJ \& Lents CA 2015 Relationships between day one piglet serum immunoglobulin immunocrit and subsequent growth, puberty attainment, litter size, 
and lactation performance. Journal of Animal Science 93 2722-2729. (https://doi.org/10.2527/jas.2014-8535)

Vogel C \& Marcotte EM 2012 Insights into the regulation of protein abundance from proteomic and transcriptomic analyses. Nature Reviews Genetics 13 227-232.

Werb Z \& Chin JR 1998 Extracellular matrix remodeling during morphogenesis. Annals of the New York Academy of Sciences 857 110-118. (https://doi.org/10.1111/j.1749-6632.1998.tb10111.x)

Wu WZ, Wang XQ, Wu GY, Kim SW, Chen F \& Wang JJ 2010 Differential composition of proteomes in sow colostrum and milk from anterior and posterior mammary glands. Journal of Animal Science 88 2657-2664. (https://doi.org/10.2527/jas.2010-2972)

Yan W, Wiley AA, Bathgate RA, Frankshun AL, Lasano S, Crean BD, Steinetz BG, Bagnell CA \& Bartol FF 2006 Expression of LGR7 and
LGR8 by neonatal porcine uterine tissues and transmission of milkborne relaxin into the neonatal circulation by suckling. Endocrinology 147 4303-4310. (https://doi.org/10.1210/en.2006-0397)

Received 26 October 2017

First decision 13 November 2017

Revised manuscript received 20 December 2017

Accepted 12 January 2018 